\title{
A \\ Investigations of the Potassium-Argon Method of Age Determination Using Solid Isotopic Dilution and Gas Removal by Crushing
}

Abstract:

Preliminary work on a new technique of isotopic dilution analysis useful in the measurement of the radiogenic argon content of rocks or mineral samples in age determination is reported. Argon-39 is added to the samples as the diluting isotope dissolved in a solid glassy silicate which approximates the pertinent properties of the sample. Crushing as well as melting can be used. to extract the representative portion of gas needed to apply the isotopic dilution method. In the preliminary investigations orderof-magnitude agreement was obtained with the argon content of samples determined by conventional techniques.

The possibilities of the method are pointed out (1) for the elimination of uncertainties about complete extraction of argon from samples, (2) for the use of radioactive counting of argon-39 as a determinative technique, and (3) for the preferential removal of air contamination by crushing to enable extension of the potassium-argon method to younger ages.

\section{LEGAL NOTICE}

This report was prepared as an sccount of Government sponsored work. Nelther the United States, nor the Commission, nor any person acting on behalf of the Commission: racy, completeness, or usefulness of the informattosed or impled, with respect to the accuof any informatton, apparatus, method, or process disclosed in this report may not infringe

privately owned rights; or
B. Assumes any liablitties with respect to the use of, or for damages resulting from the of any information, apparatus, method, or process disclosed in this report.

As used in the above, "person acting on behalf of the Commission" includes any employee or contractor or the Commission, or employee of such contractor, to the extent that dieseminates, or provides acess to, any inform with the Commioulut, or his employment with such contractor.
This paper was submitted for publication in the open literature at least 6 months prior to the issuance date of this Microcard. Since the U.S.A.E.C. has no evidence that it has been published, the paper is being distributed in Microcard form as a preprint. 


\section{DISCLAIMER}

This report was prepared as an account of work sponsored by an agency of the United States Government. Neither the United States Government nor any agency Thereof, nor any of their employees, makes any warranty, express or implied, or assumes any legal liability or responsibility for the accuracy, completeness, or usefulness of any information, apparatus, product, or process disclosed, or represents that its use would not infringe privately owned rights. Reference herein to any specific commercial product, process, or service by trade name, trademark, manufacturer, or otherwise does not necessarily constitute or imply its endorsement, recommendation, or favoring by the United States Government or any agency thereof. The views and opinions of authors expressed herein do not necessarily state or reflect those of the United States Government or any agency thereof. 


\section{DISCLAIMER}

Portions of this document may be illegible in electronic image products. Images are produced from the best available original document. 
In the determination of ages by the potassium-argon method the generally accepted technique in present practice is to determine the amount of radiogenic argon present in the sample by the method of isotopic dilution, with argon-38 as the diluting isotope. In the present research a new technique has been investigated in which argon-39 is used as the diluting isotope, and is added dissolved in an artiflcial silicate which approximates the pertinent properties of the rock being analyzed. The ease of handling and measurement involved in such a procedure is apparent.

Fechtig et al. (I) have reported the use of neutron generated argon-39 in natural silicates and in $\mathrm{KCl}$ to measure the diffusion characteristics of argon in these substances. Bombardment generated argon-37 also has been used in age (2) and diffusion measurements (3).

For the exploratory experiments a sample of potassium silicate glass was prepared as a melt from pure silica glass powder and analyzed grade potassium carbonate, and was homogenized by heating at $1450^{\circ} \mathrm{C}$. for three hours. The potassium content of the product was $10.8 \%$. The resultant clear glass was crushed to 40 to 60 mesil size in a diamond mortar, and was activated in the Brookhaven graphite reactor in the fast neutron section. Argon-39 was produced by the reaction --

$$
\mathrm{K}^{39}(\mathrm{n}, \mathrm{p}) \mathrm{Ar} \mathrm{r}^{39}
$$

After removal from the reactor, and "cooling" of short-lived activities, the samples were colored purple from neutron structural 
interactions. Annealing at $200^{\circ} \mathrm{C}$. for two hours removed this color.

The annealed samples were carefully analyzed for argon-39 content by melting in an ultra-high vacuum system. The evolved gases were purified by condensation at liquid nitrogen temperatures and by gettering with titanium sponge. Isotopic dilution with an argon-38 enriched spike was used, and rinal determination of argon was made with an inert gas mass spectrometer (4). The argon-39 content was $8.54 \pm 0.17 \times 10^{-7}$ standard cc. per gram.

In use the argon-39 spike was added, dissolved in a veighed amount of ground and sized artificial silicate, to a known veight of similarly sized rock or mineral being analyzed for radiogenic argon-40. The contamination of the sample with air argon-40 is the factor which limits the accuracy and usefulness of the potassiumargon method, especially for young minerals. This may amount to as much as $10^{-5}$ standard cc. and can completely swamp the radiogenic argon-40 for rocks of ages less than ten million years. Therefore as a firot step the cuilibined samples should be subjected to a treatment to preferentially remove or reduce this contamination. One such treatment is discussed below. For analysis, samples were placed in an apparatus to remove the required representative portion of the argon by melting or crushing, and to purify this gas by suitable freeze-out and gettering (4). Extraction by melting was carried out in a molybdenum crucible at temperatures from 
$1600^{\circ}-1800^{\circ} \mathrm{C}$. It should be emphasized that since only a representative sample of gas from the mineral is needed for analysis by this method, the degree of completeness of extraction of the gas from the sample is not of concern.

For vacuum crushing the apparatus used was a narrow mortar of stainless steel attached to the ultrahigh vacuum system through a glass-to-metal seal. The pestle was a stainless steel piston loosely fitted into the mortar, and attached by a rod to a soft iron armature within the glass portion of the system. The pestle was lifted once a second by this iron core actuated by a solenoid located outside the apparatus. It was allowed to fall under its own welght to crush the sample. The temperature of the crusher could be controlled by external baths or furnaces for degassing or for temperature controlled runs. After a typical run of 17 hours a sample was found to have been reduced from 40-60 mesh to $60 \%$ through a 200 mesh sieve. Gas was copiously evolved during this crushing process, although the crusher was not as efficient as it might be.

Measurement of the argon peaks of the purified gas was made with the inert gas bakeable mass spectrometer. By determination of the 36,39 and 40 peak ratios, a correction for air argon-40 was applied, and the volume of radiogenic argon- 40 in the mineral sample calculated according to the method of isotopic dilution. The radioactivity of the argon-39 suggests an alternate 
method of measurement. If the air argon contamination can be made negligible by a suitable pretreatment (see below), the total volume of the purified argon in a representative gas sample can be measured, and radioactive counting used to determine the argon-39 content. These two measurements would give the argon-40 to argon-39 ratio necessary for the calculation of the radiogenic argon-40 content of the original mineral sample by the dilution method.

The validity of the application of the isotopic dilution procedure in these instances depends on the identity of behavior of the argon-39 in the spike, and the radiogenic argon-40 in the mineral. After intermingling by melting there would be little question of this, but during pretreatment for removal of air contamination, or during heat-up to the melting point, there may be some uncertainty that the behavior of the isotopes of argon will be the same in the different ailicabes. The property of importance would be the rate at which argon-39 diffuses from the artificial samples relative to the difrusion rate of radiogenic argon-40 in natural silicates at similar temperatures. Therefore the diffusion constant $\underline{D}$ was used to neasure the efficiency of the annealing of the structural damage produced by neutron bombardment, and for comparison of the diffusion of the various argon isotopes. The particles were assumed to be spheres of effective radius a and diffusion was evaluated as $\underline{D} / \mathrm{a}^{2}$, thus including the particle 
size factor and eliminating the uncertainties in its determination. This function could be calculated from the fraction of argon removed during a heating treatment according to well established models for the solution of the Fick diffusion equation (5). The heating for diffusion measurements was carried out in the extraction system at temperatures between $500^{\circ}$ and $1000^{\circ}$ for known periods of time. The gas removed was spiked, purified and measured with the inert gas mass spectrometer as was done for total argon determinations. The diffusion values calculated from these measurements are show in the (a) section of Figure 1 . It will be noted that the diffusion of argon-39 in the artificial samples was the same, within experimental error, as that of radiogenic argon-40 from the natural glasses and microcrystalline rock (dolerite) measured during this work. Also it can be seen that there is little significant difference for the diffusion of atmospheric argon-40, despite the intuitive asoumption thal this argon would be held on surfaces or in microcracks, and would be released at an entirely different rate.

The release of gas on crushing was also investigated in a similar manner. The most generally accepted relationship for the crushing oi brittle materials is Rittinger's Law, which has been most thoroughly investigated by Gross (6). This law states that. the amount of new surface exposed in crushing is proportional to the energy expended. The new surface vill be a function of $\underline{a}^{2}$, 
the radius of the particles resulting from such a crushing. As a convenience for plotting we can again use the $\mathrm{D} / \mathrm{a}^{2}$ function, where $D$ now is a desorption coefficient for the gas leaving the newly exposed surface. Also we can plot this as a function of the temperature at which the crushing was conducted. This has been done in the right hand section (b) of Figure 1. We note that there is little temperature dependence for gas removal by this process. The rate of removal depends mainly on the rate at which new surface is exposed, in other words, on the efficiency of the crushing process. Most significant is the similar desorption coefficients of radiogenic argon-40 and argon-39, and the dissimilarity in the coefficient for air argon-40 release from these same substances. Again using the analogy with diffusion release, the "half-life" for removal of a gas is equal to $0.03 \mathrm{a}^{2} / \mathrm{D}$ for particles assumed to be spherical (5). For air argon-40 renoval in this particular crushing machine this is about 80 hours, as opposed to 8000 hours for the other argon isotopes. One can be optimistic, then, that these can he decreaocd to such a value as would make it possible to preferentially remove the air argon-40 contamination within a reasonable time by improvement in the design and efficiency of the vacuum crushing device.

Using the method of isotopic dilution with argon-39, measuremento of the radiogenic argon-40 content of two test materials were made (Table 1). These samples were a young volcanic 
glass (KA-40) and a very old pegmatite muscovite mica which represented extremes of argon content. Both samples were kindly supplied by W. A. Bassett, as were the results for the conventional analyses of the mica. For the argon-39 spiked sarnples each group represents fractions from a single sample while heating at the temperatures indicated, with or without crushing. The results show order-of-magnitude agreement. The factors which may contribute to this poor precision are under investigation. The preliminary results presented in this report, while encouraging, should be considered exploratory $(7,8)$.

John J. Naughton

Department of Chemistry

Brookhaven National Laboratory Upton, Long Island, New York

\author{
Lepartment of Chemistry \\ University of Hawaii \\ Honolulu 14, Hawaii
}


References and Notes

(I) H. Fechtig, W. Gentner and S. Kalbitzer, Geochim. et Cosmochim. Acta 25297 (1961).

(2) R. W. Stoenner and J. Zahringer, Geochim. et Cosmochim. Acta 1540 (1958).

(3) H. Fechtig, W. Gentner and J. Zahringer, Geochim. et Cosmochim. Acta 1970 (1960).

(4) 0. A. Schaeffer, BNL 581, Brookhaven National Laboratory (1959).

(5) D. Reichenberg, J. Amer. Chem. Soc. 75589 (1953).

(6) J. Gross, U.S. Bur. Nines, BuIl. 402 (1938).

(7) This research was performed under the auspices of the U.S. Atomic Energy Commission.

It is a pleasure to aclnowledge the unstinting help and encouragement of Oliver A. Schaeffer in all phases of this work, and the many helpful discussions with other nembers of the geochemistry group, Chemistry Department, Brookhaven National Laboratory.

(8) Contribution Series, No. 34, Hawaii Institute of Geophysics. 
Table 1

Volume of Radiogenic Argon-40

Standard cc. per Gram of Sample

Argon-39 Spike

Heating Only

Volcanic

Glass

$\mathrm{KA}-40$

$1.67,1.79 \times 10^{-7}\left(500^{\circ}\right)$

$6.38 \times 10^{-7}$ (me1t)
Argon-39 Spike

Crushing

$1.87 \times 10^{-7}\left(250^{\circ}\right)$

$3.53,1.36,5.74$,

$$
4.90 \times 10^{-7}\left(500^{\circ}\right)
$$

$1.43,1.47$,

$4.11 \times 10^{-7}\left(500^{\circ}\right)$
$1.45 \times 10^{-3}(\mathrm{mel} t)$
$0.71 \times 10^{-3}$ (melt)
$1.09,3.63 \times 10^{-3}$
$\left(500^{\circ}\right)$

Argon-38 Spike

Conventional

$2.12,2.28 \times 10^{-7}$

(melt)
$1.76,1.85 \times 10^{-3}$
(melt) 


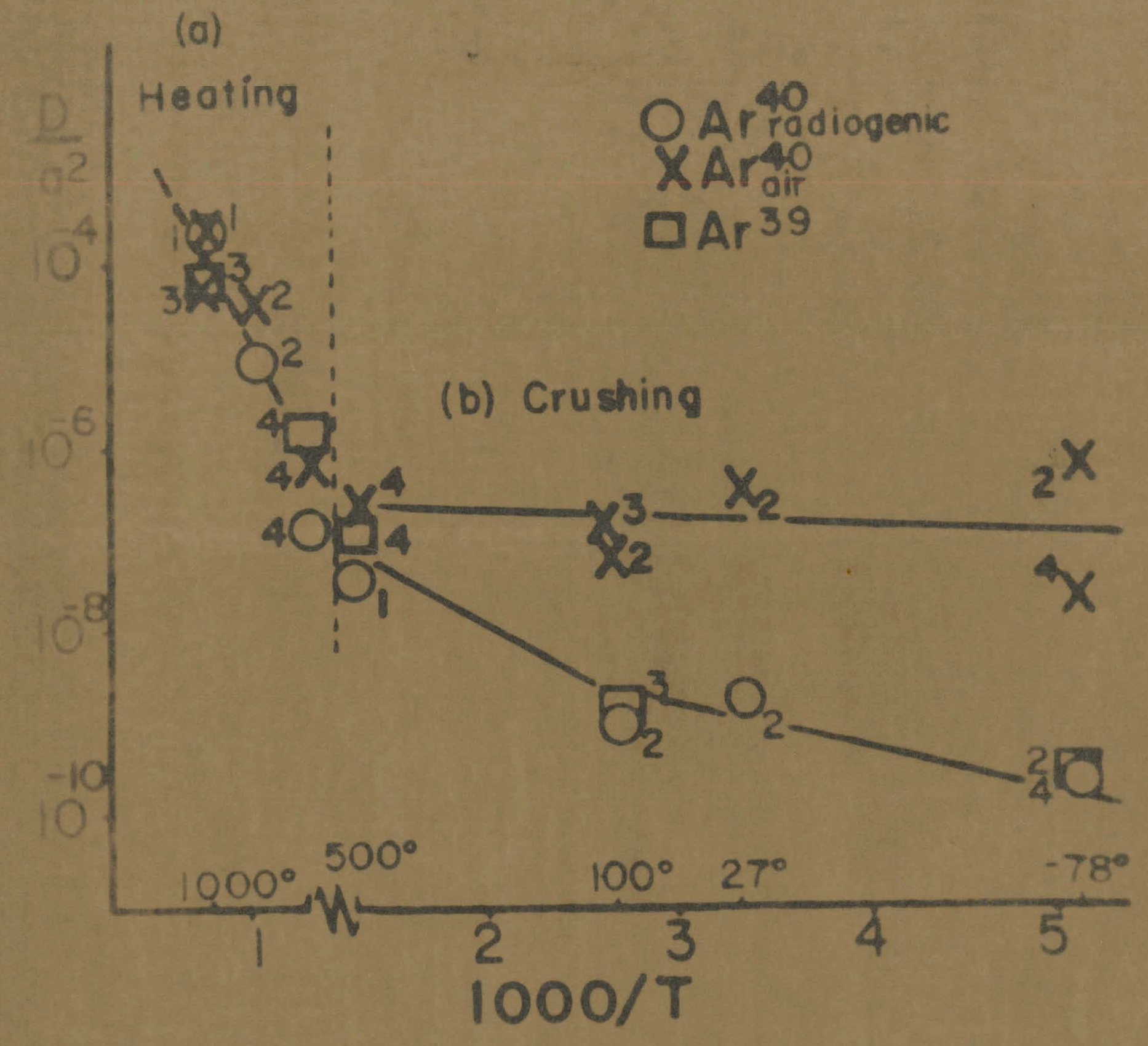


-11-

Figure 1. Temperature dependence of the release of argon isotopes by (a) lieáling und (b) crushing. 1. Volcanic glass. 2. Dolerite. 3. Artificial glass. 4. Artificial glass - volcanic glass mixture. 